\title{
Lumped parameter model and experimental tests on a pressure limiter for variable displacement pumps
}

\author{
Paola Fresia ${ }^{1}$ and Massimo Rundo ${ }^{1 *}$ \\ ${ }^{1}$ Department of Energy, Politecnico di Torino, C.so Duca degli Abruzzi 24, 10129, Turin, Italy
}

\begin{abstract}
The paper presents the lumped parameter model of a pressure limiter for axial piston pumps developed in the Simcenter Amesim ${ }^{\circledR}$ environment. The control includes both the absolute and differential (load sensing) pressure limiter in a single body. The continuous position valve was tested experimentally alone on a test rig in order to estimate the discharge coefficients required for tuning the model. The tests were performed at imposed positions of the spool and the corresponding modulated pressure and control flow through the valve were measured. A contactless transducer was used for measuring with a very high accuracy the spool position. The influence of the bleed orifice on the pressure gain was also measured experimentally. It was found that the discharge coefficients have a significant influence on the hydraulic characteristic of the valve with also a consequence on the dynamic behavior of the entire displacement control.
\end{abstract}

\section{Introduction}

The aim of the pressure controls in fluid power pumps is to modify automatically the displacement of the machine in order to maintain constant the delivery pressure (absolute limiter) or the pressure drop across a direction control valve (differential limiter). The simplest architecture is the direct acting control, where the delivery pressure generates a torque on the swash plate, typically by means of a hydraulic actuator, acting against a spring that decides the pressure setting [1]. However, the drawback of this simple solution is the high dependence of the regulated pressure by the current swash plate angle. An almost perfect pressure regulation can be obtained by means of piloted controls, made up of a continuous position pilot valve, sensitive to the delivery pressure, and one or two linear actuators. In more complex solutions a pressure reducing pilot valve can also be present [2]. Aim of the continuous position valve is to modulate a control pressure in an actuator up to the achievement of the condition of equilibrium, for which the displacement is reduced. The system is closed-loop controlled, where the linearized coefficients of the continuous position valve play the role of gains in the block diagram of the state variable model [3].

\footnotetext{
* Corresponding author: massimo.rundo@polito.it
} 
Typically, the pilot valve is provided with 3 ports and it could be simply hydraulicmechanic or electro-hydraulic [4]. In simpler solutions the pressure can be modulated by a two-port valve and a fixed restrictor [1]. Regardless of the actuation type, its design is crucial for both the steady-state and the dynamic performance of the displacement control, in terms of accuracy, transient time and stability [6-8].

Many studies were performed on pumps with this type of displacement control. For instance, Gilardino et al. [9] built a lumped parameter model of an axial piston pump with both absolute and differential pressure limiter. Casoli et al. [10] developed a model of a similar pump for studying the active control of the pressure ripple. Detailed CFD models of an entire axial piston pump are available, but without the control [11, 12]. On the other hand, 0D pump models have been implemented in a more complex circuit for a systemlevel analysis aimed at evaluating the influence of the control setting on the power consumption [13]. It is straightforward that a reliable and predictive model of a pump implies a calibration of the control valve coefficients, which play a fundamental role also in the development of new displacement control strategies [14]. In [15] a 0D model of a vane pump where the discharge coefficients of the control valve were tuned by means of CFD simulation is reported.

As alternative, the discharge coefficients, as well as the flow and pressure gains, can be measured experimentally. However, a direct measurement of such coefficients for tuning and validating the valve models is not an easy task, due to the very small effective stroke of the spool, typically of the order of $0.1 \div 0.2 \mathrm{~mm}$. Moreover, it is practically impossible to determine the control flow if the valve is mounted on the pump, unless major modifications of the component are carried out.

In this paper a $0 \mathrm{D}$ model of a differential (load sensing) and absolute pressure limiter is presented. The modulated pressure, the control flow as well as the pressure and flow gains have been measured experimentally on a test rig for electro-hydraulic servovalves. The developed methodology can be used for tuning a 0D model and it has been proved to be very accurate.

\section{Component description}

The load sensing control shown in Fig. 1 is mounted on the Rexroth A10VSO series pumps and includes in a single body the differential (DPL) and the absolute (APL) pressure limiters. At rest, the two identical spools connect the port A of the displacement actuator to port $\mathrm{T}$, while port $\mathrm{P}$ remains closed. The delivery pressure acts, thanks to a radial and axial hole in each spool, on the left surfaces and tends to move the spools to the right against the adjustable springs. In the spring chamber of the DPL the load sensing pressure acts by means of a channel perpendicular to the section plane, while the spring chamber of the APL is connected to the T port.

The hydraulic scheme of the entire control is shown in Fig. 2a, where a variable restrictor simulates a proportional directional control valve (DCV). When the control is in saturation, the pump displacement is maintained at the maximum value thanks to the contrasting actuator with surface "a" and to the non-adjustable spring, while the intervention of one of the two controls generates the increment of the pressure in the displacement actuator with surface "A"; as a consequence the pump displacement is reduced. If the delivery pressure is lower than the value $p^{*}$, the DPL regulates in order to impose $p_{p}=p_{u}+s$. If the delivery pressure achieves $p^{*}$, the APL regulates in order to maintain $p_{p}=p^{*}$ (pressure saturation). In such a case, since the pressure drop across the direction control valve will be lower than $s$, the APL will be connected to the port $\mathrm{T}$ through the spool of the DPL, which, in turn, will be at rest. The lands devoted to control the flow areas are indicated with 1 for P-A and with 2 for A-T. 
The fixed orifice St1 allows venting the load sensing signal when the direction control valve is closed: this solution is used if the direction control valve does not allow connecting the load sensing signal to the reservoir in the central position. Vice versa the restrictor St1 is not strictly necessary.

The couple of restrictors St2 (bleed) is drilled on a plug that can be rotated through a screwdriver. In the position shown in Fig. 1 the restrictors are open, while they can be closed by rotating the plug by 90 degrees. Such restrictors allow lowering the pressure gain of the control in order to avoid a possible instability.

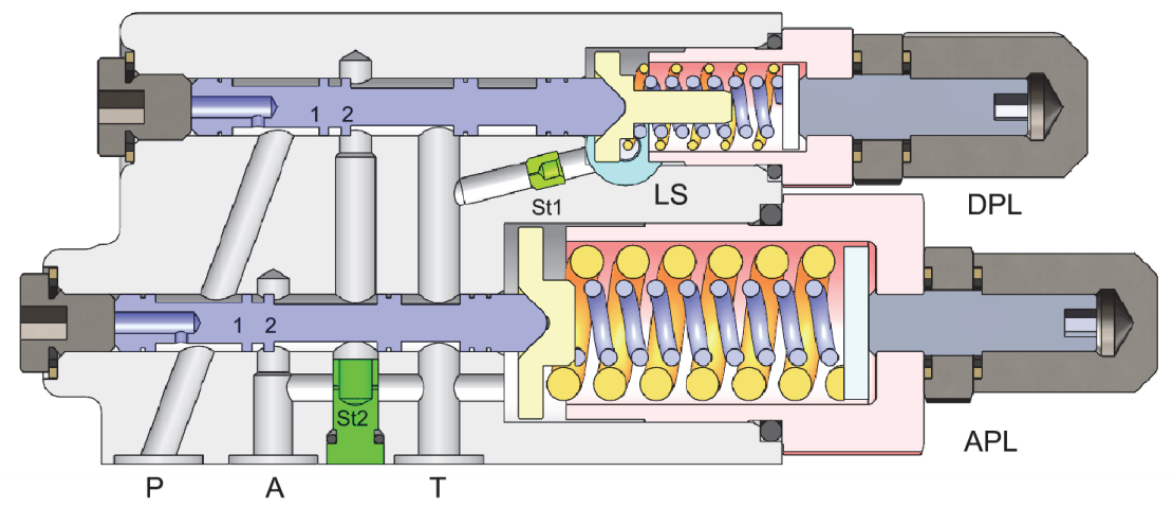

Fig. 1. Section view of the displacement control.

As demonstrated later, the dimensional tolerances have a strong influence on the control behavior; hence for a rigorous validation of the simulation model, the geometry of the flow areas must be evaluated very accurately. In particular, with reference to Fig. $2 b$, for the APL control the diametrical clearance spool-clearance $D s-D c$ and the hole diameter $D f$ were measured with a precision of $1 \mu \mathrm{m}$, while the distance between the outer faces of the lands $L$ with a resolution of $0.01 \mathrm{~mm}$. A very precise measurement of the bleed orifice diameters was not possible. By means of different metal wires, the range between $0.55 \mathrm{~mm}$ and $0.7 \mathrm{~mm}$ was determined. However, the experimental tests described later have shown that diameters in the lower range would have implied values of the discharge coefficient quite unusual for the simple geometry of circular hole, hence a diameter of $0.65 \mathrm{~mm}$ was assumed.

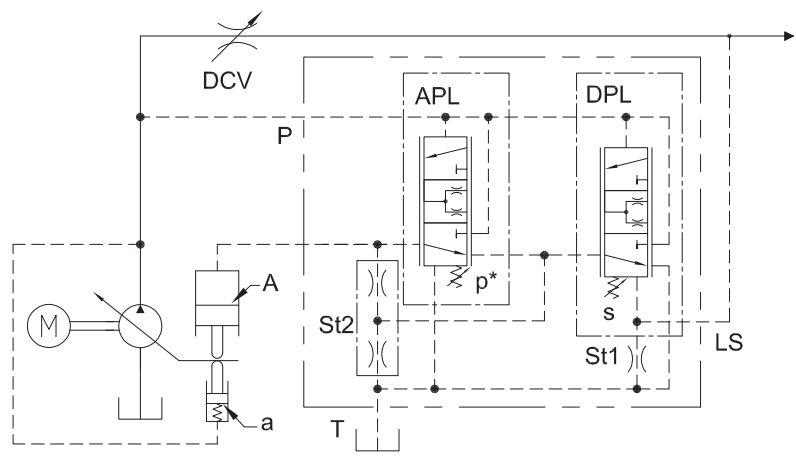

(a)

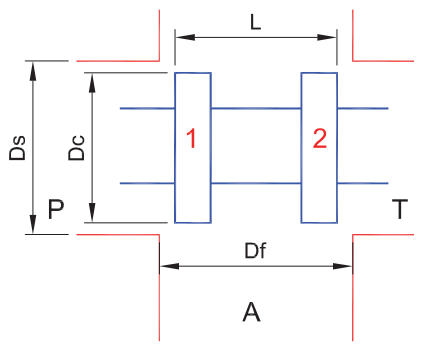

(b)

Fig. 2. Hydraulic scheme of the displacement control (a). Measured quantities for the APL (b). 


\section{Simulation model}

The model in the Simcenter Amesim environment that reproduces the hydraulic circuit shown in Fig. 2a is reported in Fig. 3. On the right part, the two spools of the DPL and APL can be identified. The components indicated with the numbers 1 and 2 simulate the flow areas $A(x)$ determined by the respective lands shown in Fig. 1 as function of the spool position $x$.

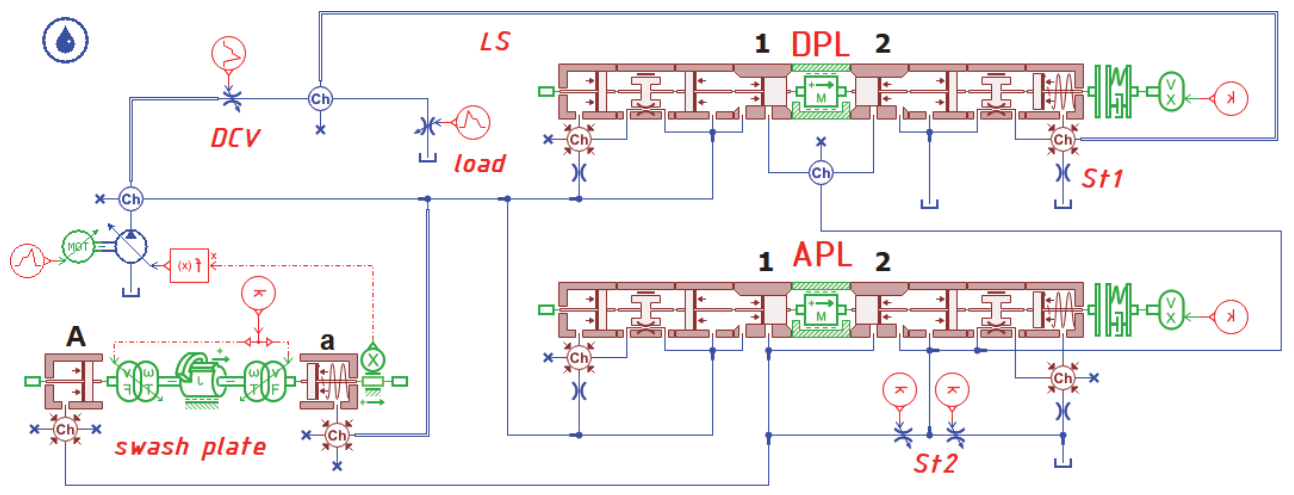

Fig. 3. Model in the Simcenter Amesim environment of the entire displacement control.

The flow rate is calculated with the classical Eq. (1) for turbulent regime depending on the pressure drop $\Delta p$ and on the fluid density $\rho$ :

$$
Q=C_{d} A(x) \sqrt{\frac{2 \Delta p}{\rho}}
$$

Usually the discharge coefficient $C_{d}$ is expressed as function of the flow number defined as:

$$
\lambda=\frac{d_{h}}{v} \sqrt{\frac{2 \Delta p}{\rho}}
$$

being $d_{h}$ the hydraulic diameter and $v$ the kinematic viscosity. The expression for the discharge coefficient implemented in the Amesim environment is given by Eq. (3):

$$
C_{d}=C_{d \max } \tanh \left(\frac{2 \lambda}{\lambda_{\text {crit }}}\right)
$$

where $\mathrm{C}_{d \max }$ is the asymptotic value and $\lambda_{\text {crit }}$ the critical flow number defining the transition to fully developed turbulent regime. The model considers also the leakage flow due to the radial clearance of the spools.

The two couples of coaxial springs have different free lengths, depending on the position of the control screw, hence it is possible that only the external one has a preload; for this reason, the internal spring is simulated as an elastic end-stop with an initial gap.

The $71 \mathrm{cc} / \mathrm{rev}$ axial piston pump is simulated with an ideal unit, where the displacement modulation factor is calculated as function of the equilibrium of a rotary mass representing the swash plate. The tilt angle is calculated starting from the forces exerted by the actuators.

Finally, the load and the direction control valve are simulated by variable restrictors. 


\section{Experimental facility}

The main aim of the study is the evaluation of the coefficients for tuning the simulation model. The control was mounted on a test rig for electrohydraulic servovalves installed at the Fluid Power Research Laboratory of the Politecnico di Torino, with an ISO VG-46 mineral oil; the simplified circuit, with only the components used in this study, is shown in Fig. 4. The test rig is fed by a flow generation unit made up of a variable displacement pump PU1 with absolute pressure limiter, controlled remotely, and a boost pump (PU2). The excess flow of the pump PU2 is discharged by the pressure relief valve PRV that imposes the pressure at the inlet port of the pump PU1.

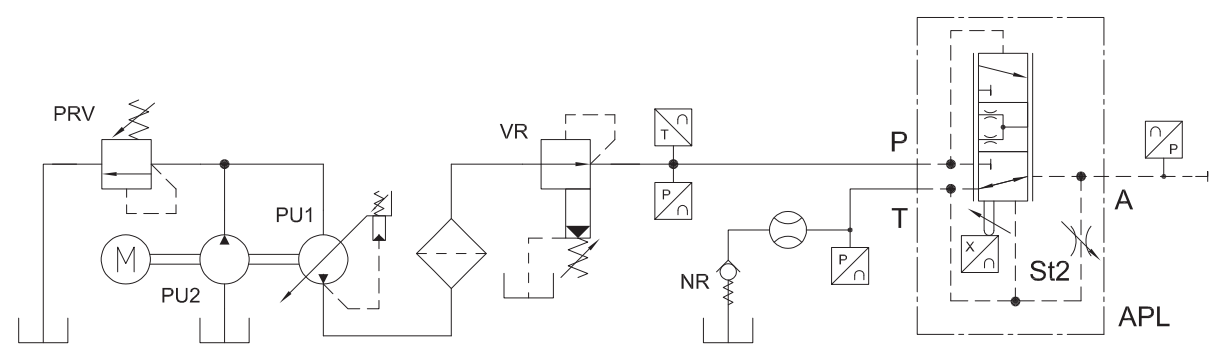

Fig. 4. Simplified hydraulic scheme of the circuit for the experimental tests on the control.

The pressure reducing valve VR is used to set the pressure at the P port of the control. Since the two spools have the same geometry, only the APL was tested, while the DPL was kept mechanically blocked at rest, hence in the hydraulic scheme the DPL has been omitted. In the APL the springs were removed and substituted by a steel spacer. During the test, the pressure at port $\mathrm{P}$ maintained the spool in contact against the spacer, so that by means of a nut and locknut it was possible to rotate the screw with a wrench in order to set the spool position.

A contactless displacement transducer KAMAN KD2300-1SUM with measuring range $1.25 \mathrm{~mm}$ and accuracy $0.1 \mu \mathrm{m}$ was used for detecting the actual position of the spool. The transducer works on the principle of the variation of the magnetic reluctance that is proportional to the gap with respect to a magnetic target. In this case the target was the flat surface of the locknut, as shown in the Fig. 5.

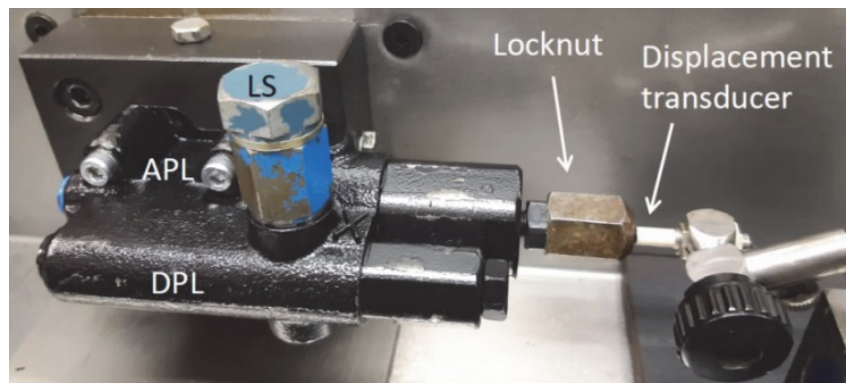

Fig. 5. Photo of the displacement control mounted on the test rig with the position transducer.

The pressure at port $\mathrm{P}$ was measured by a transducer Danfoss MBS 3050, while the pressures at ports $\mathrm{A}$ and $\mathrm{T}$ with transducers BELL \& HOWELL BHL-4100. All sensors have a measuring range $0-400$ bar and were calibrated by means of a deadweight tester.

The flow rate at port $\mathrm{T}$ was measured by a KEM ZHM02 gear flowmeter with measuring range $0.1-4 \mathrm{~L} / \mathrm{min}$, while the temperature at the $\mathrm{P}$ port by a PT100 resistance 
temperature detector. The signals were acquired by a 12-bit National Instrument data acquisition card PCI 6071E controlled by a home-made Virtual Instrument (VI) developed in the Labview ${ }^{\circledR}$ environment. The VI acquires continuously the input channels and when the steady-state conditions are reached the user can save the mean values calculated over a desired time interval.

\section{Simulation outcomes}

The tests were performed as function of the spool position with constant inlet pressure at port P. By means of a wrench, the spool position was progressively modified with small steps of about $10 \mu \mathrm{m}$ and the corresponding pressure at port A and the flow rate through the valve were acquired.

The first presented results are relative to the condition with bleed orifice closed. In this case the measured flow rate is only the flow through the metering edges of the lands 1 and 2 connected in series. Before mounting the control on the test rig, an attempt was made for correlating the positions of the spool and of the target for the displacement transducer. The method consisted in inserting a metal wire in the channel of the port A and to move the spool so that the wire was clamped by the edge of the land 1, in order to block the spool in a known position; then, by means of a caliper, the distance between the surface of the locknut and the casing of the control was measured. However, due to the very small useful stroke of the spool, this method was proved to be not reliable. Hence, the position of the spool was estimated, in retrospect, by the analysis of the experimental data. In fact, the position for which the spool is centered with respect to the ports $\mathrm{P}$ and $\mathrm{T}$ (same flow areas P-A and A-T), is identified to a first approximation by the maximum of the flow rate.

In Fig. 6a the comparison between the simulated and experimental flow rate through the valve is shown with inlet pressure at port $\mathrm{P}$ equal to $50 \mathrm{bar}$. Two repetitions of the same test are reported. In Fig. $6 \mathrm{~b}$ the corresponding pressure at port $\mathrm{A}$ as function of the spool position is shown. In the model, the parameter $\lambda_{\text {crit }}$ was left everywhere at the default value of 100 , while a proper combination of the maximum discharge coefficients P-A and A-T was found in order to obtain the same maximum flow and the same slope of the modulated pressure around the central position of the spool measured experimentally.

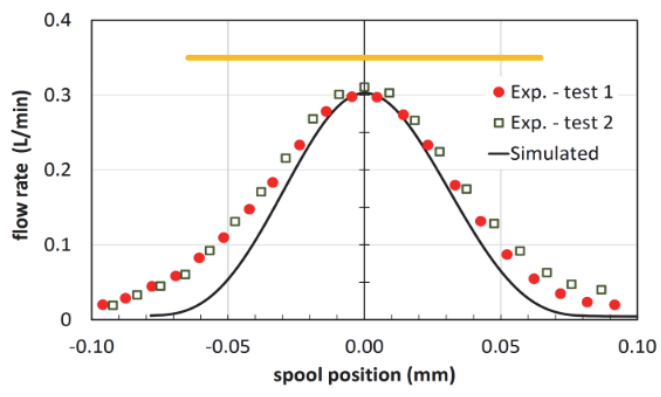

(a)

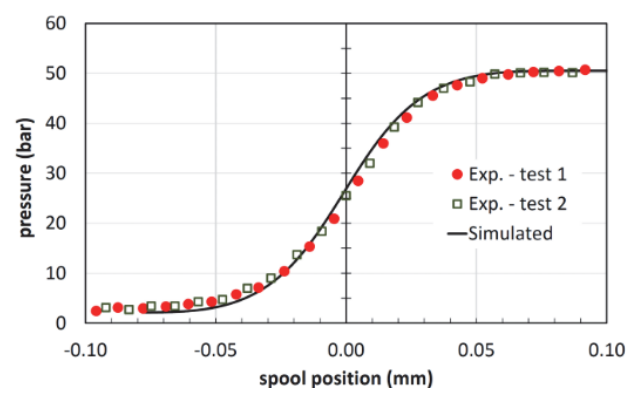

(b)

Fig. 6. Simulated and experimental flow rate (a) and pressure (b) vs. position with bleed closed and pressure $\mathrm{P}=50$ bar.

In particular $C_{d \max }=0.83$ for the connection P-A and $C_{d \max }=0.74$ for the connection A-T were used. In Fig. 6a, the horizontal yellow bar indicates the range for which ideally both flow areas P-A and A-T are open. Outside this range the flow is possible only thanks to the radial clearance spool-casing or due to the fillet radii of the spool lands. 
The modulated pressure is reproduced very well, while the flow rate in correspondence of the limits of the yellow range is underestimated. Moreover, a significant flow rate is measured when one of the two connections (P-A or A-T) is virtually closed.

The same test was repeated at 100 bar and the results are shown in Fig. 7a and in Fig. $7 \mathrm{~b}$. The same values of $C_{d \max }$ are suitable for obtaining the maximum flow rate. The underestimation of the flow rate when the valve should be closed is even more evident. It was found that for strokes of the spool higher than $0.2 \mathrm{~mm}$ and lower than $-0.2 \mathrm{~mm}$ the flow rate tends to a value lower than $0.05 \mathrm{~L} / \mathrm{min}$ (although such a value is outside the measuring range of the flow meter). This flow represents the sum of the leakages in the APL and in the DPL across the entire length of the spool lands 1 or 2 (condition of minimum leakage); since the two valves are geometrically similar, it can be assumed that the leakage at $100 \mathrm{bar}$ in the DPL, which is maintained completely closed, could be the order of $0.02 \div 0.03 \mathrm{~L} / \mathrm{min}$. Hence, the discrepancy of the flow rate around the positions $\pm 0.05 \mathrm{~mm}$ in Fig. $6 \mathrm{a}$ and in Fig. 7a could be due to a limit of the mathematical model in calculating the flow around the condition of critical lap, where the transition between the Eq. (1) and the Poiseuille equation for laminar flow is managed through a proper correction term [16].

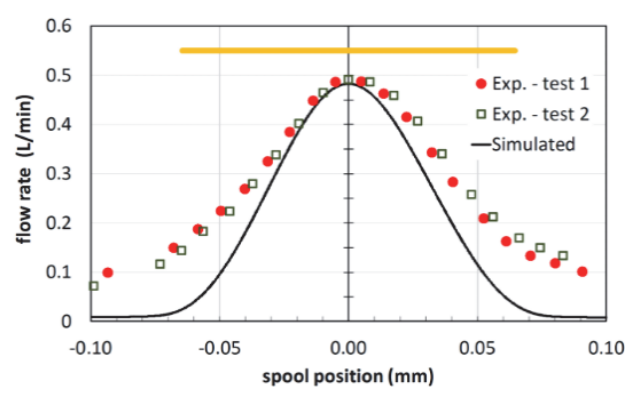

(a)

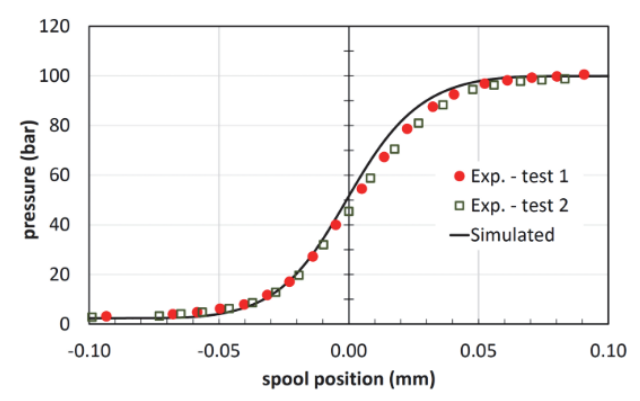

(b)

Fig. 7. Flow rate (a) and pressure (b) vs. position with bleed closed and pressure $\mathrm{P}=100$ bar.

Another reason could be the uncertainty of some geometric tolerances (the fillet radii of the spool lands and of the casing holes or the rounding tolerances) and of the current eccentricity between the spool and the casing. An optical analysis of the spool lands has highlighted sharp edges with a negligible and not quantifiable fillet radius. Moreover, CFD analyses [17] have shown that high values of the fillet radius lead to excessive flow rates around the central position of the spool. By means of the CFD simulations, it was found that $7 \mu \mathrm{m}$ for all edges allows obtaining the same experimental flow rate for the position 0 $\mathrm{mm}$ of the spool. Hence such a value was used also in the $0 \mathrm{D}$ model.

The flow rate and the modulated pressure at 100 bar with bleed open are shown in Fig. $8 \mathrm{a}$ and Fig. $8 \mathrm{~b}$ respectively. The optimal coefficient $C_{d \max }$ equal to 0.68 was found for the bleed orifice; such a number is in line with the typical values for circular hole geometry.

The experimental methodology allows a very precise measurement of pressure and flow gains, despite the extremely short useful stroke of the spool, above all when the bleed is closed. In Fig. 9a the pressure gain, defined as the derivative of the pressure at port A as function of the spool position, is shown for two different repetitions of the test with bleed orifice closed and open. A similar graph is shown in Fig. $9 \mathrm{~b}$ for the flow gain, defined as the derivative of the flow rate through the land 1 (connection P-A) as function of the spool position. In both cases the repeatability is clearly very good. 


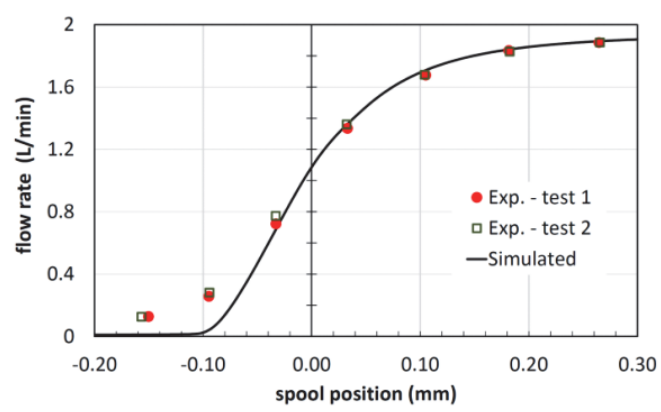

(a)

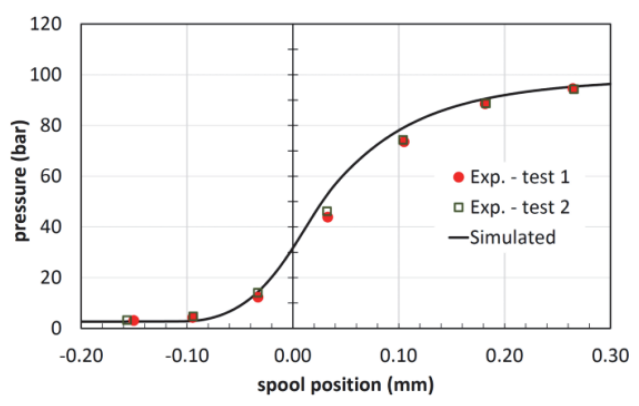

(b)

Fig. 8. Flow rate (a) and pressure (b) vs. position with bleed open and pressure $\mathrm{P}=100$ bar.

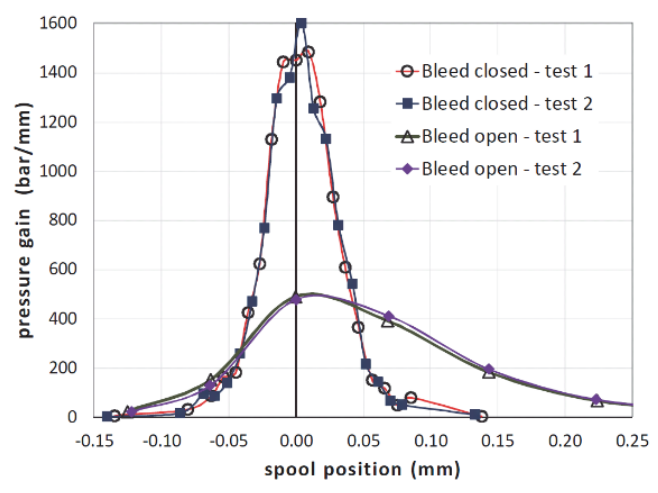

(a)

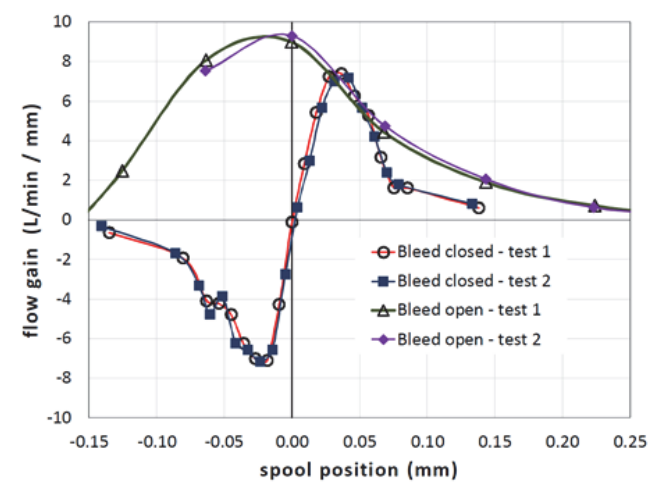

(b)

Fig. 9. Experimental pressure (a) and flow (b) gains vs. displacement with pressure $P=100$ bar.

\subsection{Influence of the geometric tolerances and of the elastic deformation}

In Fig. 10a the flow rate at 100 bar with bleed orifice closed for different values of the fillet radius of the metering edges is reported. The simulations were performed using the same value of the fillet radius for all edges involved in defining the flow areas. The increment of the fillet radius allows a better agreement with the experimental tests for small openings; however, the increase of the maximum flow rate is also observed. Hence high values of the fillet radii cannot reproduce correctly the flow rate in the entire working range, unless the discharge coefficient is significantly reduced only around the central position. However, such a reduction was not observed in CFD simulations. The distance $L$ between the lands 1 and 2 has the same effect, as shown in Fig. 10b where the variation with respect to the measured value is reported. However, an absolute deviation higher than the resolution of the instrument used for the measurement $(0.01 \mathrm{~mm})$ is not reasonable.

An attempt was made for determining a relationship between the discharge coefficients and the flow number $\lambda$ in the central position of the spool. A significant range for $\lambda$ can be obtained only with a pressure variation at port $\mathrm{P}$ of the order of $200 \mathrm{bar}$, corresponding to a pressure drop across each metering edge of the lands 1 and 2 of about 100 bar. Some tests were performed at constant position of the spool with variable inlet pressure; however, it was found that the elastic axial deformation of the spool and of the screw did not allow maintaining constant the flow areas. 


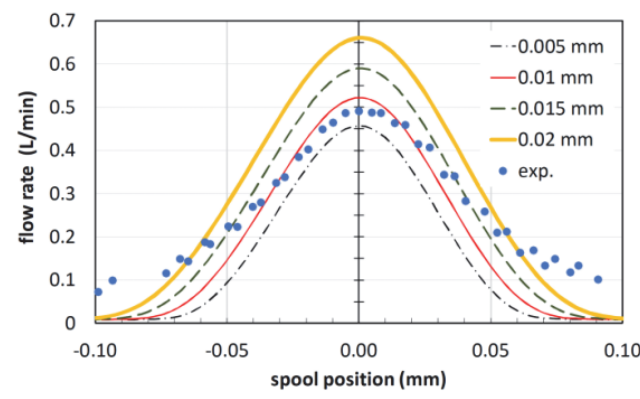

(a)

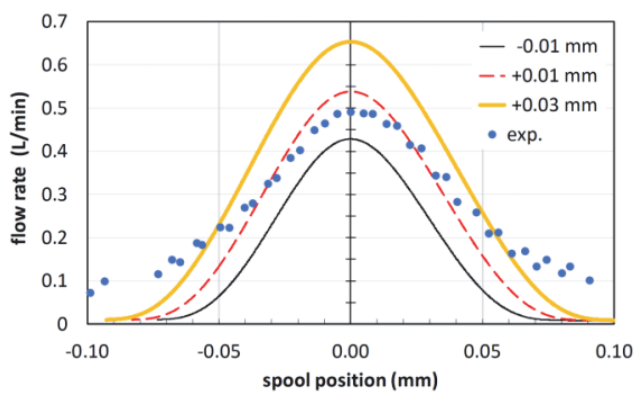

(b)

Fig. 10. Influence of the fillet radius (a) and of the spool lands distance $L$ (b) on the flow rate with bleed closed at 100 bar.

A quantification of the translation of the lands only due to the axial compression of the spool was performed by means of a FEM analysis with Solidworks Simulation ${ }^{\circledR}$. In Fig. 11 the constraints and the load conditions on the spool are shown for a delivery pressure of 250 bar. The deformation field reported in the same figure shows a variation of the position of the lands of more of $8 \mu \mathrm{m}$. Such a deformation could appear negligible. However, if in the $0 \mathrm{D}$ model an equivalent rigid translation of the spool starting from the central position is simulated, a variation of the flow areas up to $15 \div 20 \%$ is observed (Fig. 12a). Moreover, also a significant percent variation of the modulated pressure is induced (Fig. 12b). It is evident that with such variations of the flow area and of the pressure drop an estimation of the discharge coefficient with a reasonable accuracy is not possible.

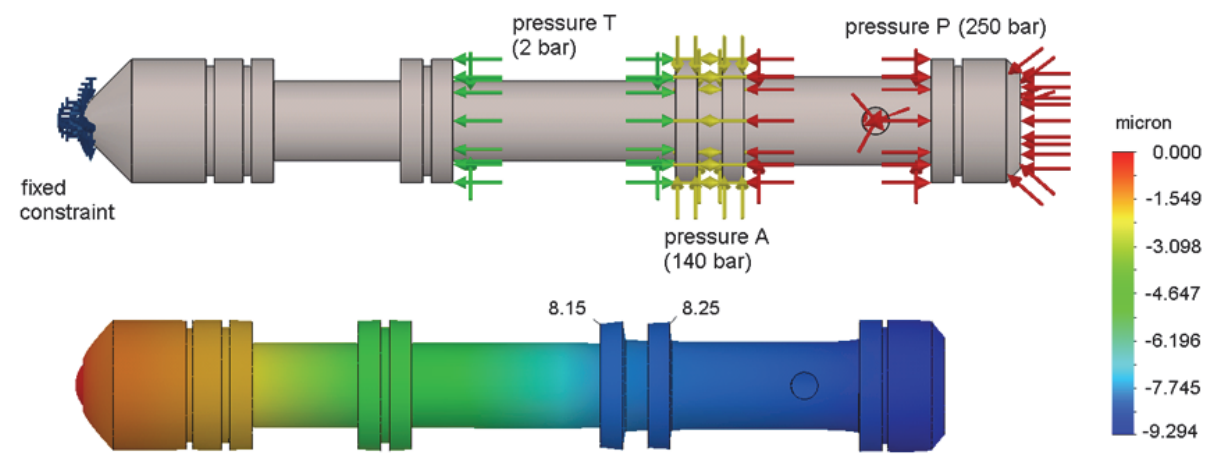

Fig. 11. Load conditions and deformation field of the spool with inlet pressure 250 bar.

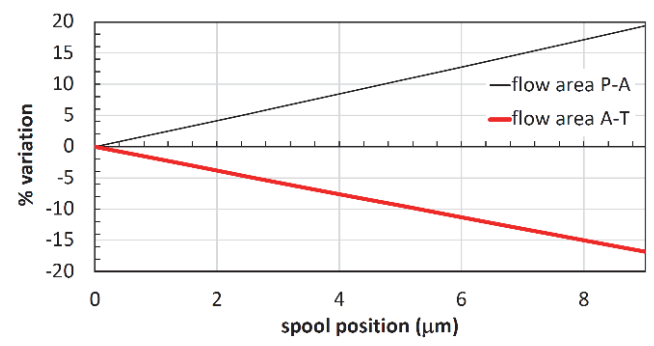

(a)

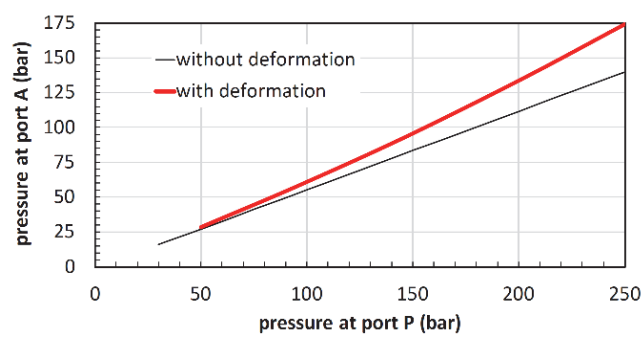

(b)

Fig. 12. Percent variation of flow areas (a) and modulated pressure vs. pressure at port $P$ (b) due to the spool deformation. 


\subsection{Influence of the discharge coefficient on the stability}

In this section, the importance of the tuning of the discharge coefficients in the 0D model of the control is demonstrated. The entire model shown in Fig. 3 was used for simulating a transient with a sequential intervention of the DPL $(s=20$ bar $)$ and of the APL $\left(p^{*}=100\right.$ bar). A CFD 1D model was used for the pipe between the pump and the DCV with a length of $3 \mathrm{~m}$ and diameter $16 \mathrm{~mm}$. Similarly, the same model was used for the LS line with a length of $3 \mathrm{~m}$ and diameter $4 \mathrm{~mm}$. The delivery volume of the pump and the volume downstream from the DCV were set respectively to $140 \mathrm{~cm}^{3}$ and $100 \mathrm{~cm}^{3}$. The tests were performed with the bleed orifice closed.

The pump is accelerated from 0 to $1500 \mathrm{rpm}$ in $1 \mathrm{~s}$ (Fig. 13a) with the direction control valve closed (Fig. 13b); during this stage the load sensing signal is null, since there is no flow through the restrictor simulating the load. At the time $1 \mathrm{~s}$ the DCV is open in $0.1 \mathrm{~s}$ and the DPL takes the control of the pump displacement. Finally, at $1.5 \mathrm{~s}$ the load is increased up the intervention of the APL.

To bring to evidence the importance of the discharge coefficients, the simulation was performed with three different values of the maximum discharge coefficient $\mathrm{C}_{d \max }$, used for the connections P-A and A-T of both DPL and APL. In Fig. 14 the detail of the delivery pressure when the DPL regulates is shown, while in Fig. 15 the case when the APL controls the displacement is reported. It is evident in the reported example how the value of the discharge coefficient could discriminate between a condition of stability and a condition of instability. In the particular case analyzed in this study, the use of low values, but anyway very reasonable and common, of the discharge coefficients of the order of $0.6 \div 0.7$ could lead to the wrong conclusion that the system is stable. Instead the tuning with the experimental test, even if with some uncertainties, have shown that more realistic values of the coefficients are in the range $0.75 \div 0.85$, with an evident consequence of the stability.

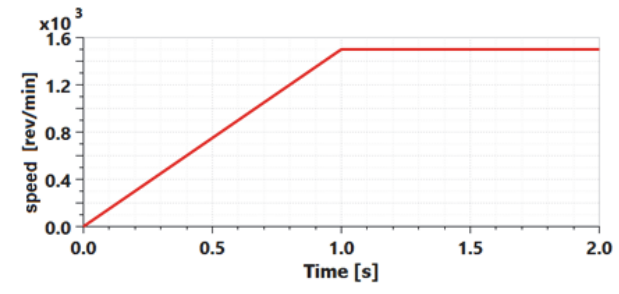

(a)

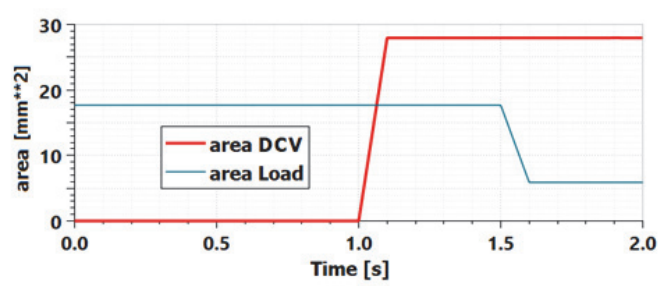

(b)

Fig. 13. Pump speed (a) and flow areas for the direction control valve (DCV) and of the load (b) as function of the time.

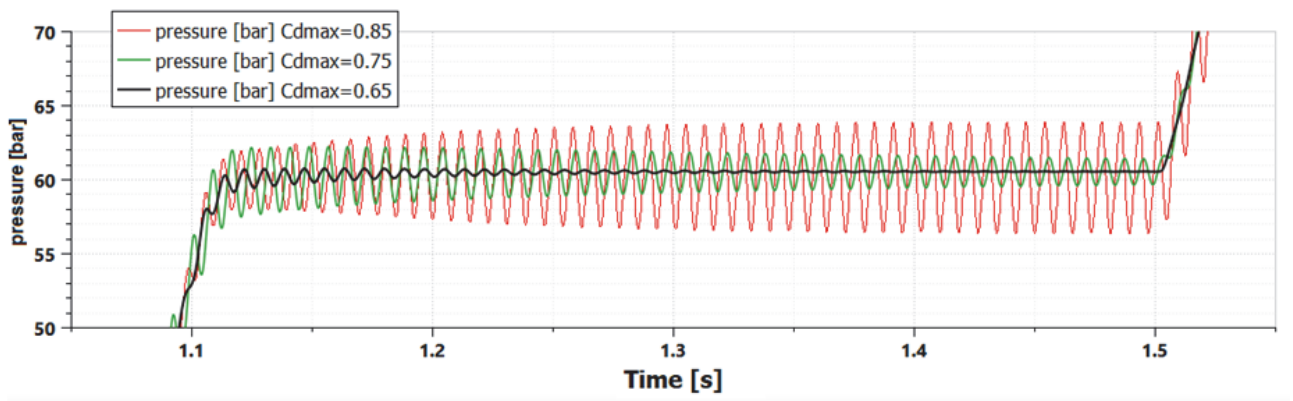

Fig. 14. Pump delivery pressure when the DPL is regulating. 


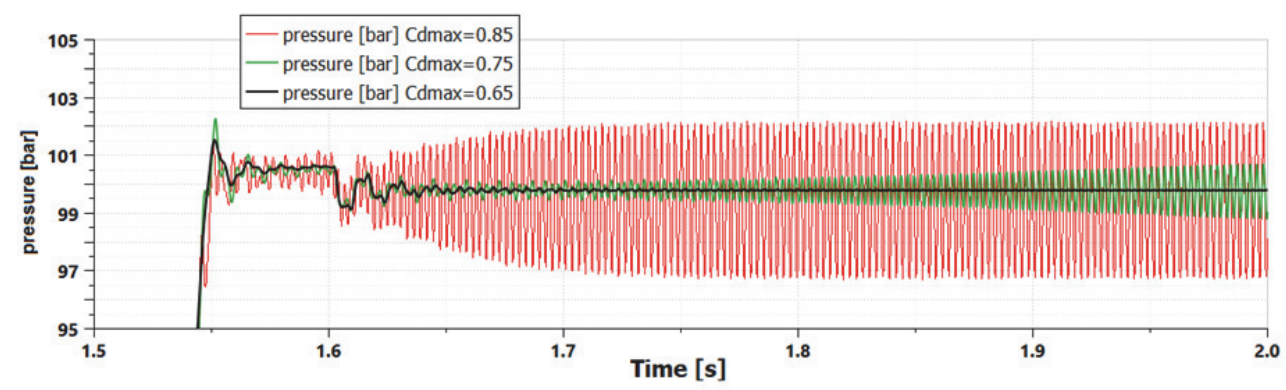

Fig. 15. Pump delivery pressure when the APL is regulating.

\section{Conclusions}

In this study the lumped parameter model of a displacement control has been developed. Moreover, an experimental procedure for evaluating the discharge coefficients has been introduced. The study has brought to evidence the influence of the discharge coefficients on the control dynamics. It was found that for some combinations of the geometric parameters of the system, a variation of the discharge coefficient in the range $0.65 \div 0.85$ can lead to the stability or instability of the control. Although the system dynamics is also influenced by other unknown parameters, such as the friction coefficients in the valves, the knowledge of the correct discharge coefficients reduces the degree of uncertainty. Moreover, it was also found that the elastic deformation for the spool generates significant variations of the flow area, making impossible to determine the influence of the flow number on the discharge coefficients as the pressure increases. However, a direct measurement of the pressure and flow gain is possible with a very good repeatability. Hence, in case of need, the model of the control could be tuned directly by means of a look-up table in order to reproduce the experimental gains.

\section{Acknowledgments}

Authors wish to thank Michele A. Pavanetto (Duplomatic Motion Solution) for the geometric measurements on the valve used for the experimental tests.

\section{References}

1. G.J. Schoenau, R.T. Burton, G.P. Kavanagh, Dynamic Analysis of a Variable Displacement Pump, J. Dyn. Sys., Meas., Control, 112(1): 122-132 (1990). DOI: 10.1115/1.2894129.

2. R.P. Jenkins, M. Ivantysynova, An Empirically Derived Pressure Compensation Control System for a Variable Displacement Vane Pump, BATH/ASME 2018 Symposium on Fluid Power and Motion Control, Sep. 12-14, Bath, UK. DOI: 10.1115/FPMC2018-8857.

3. G. Zeiger, A. Akers, Dynamic Analysis of an Axial Piston Pump Swashplate Control, Proc. IMechE, Part C: J. Mech. Eng. Sci., 200: 49-58 (1986). DOI: 10.1243/PIME_PROC_1986_200_093_02.

4. W. Backè, Electro-hydraulic pump control, $1^{\text {st }}$ JFPS International Symposium on Fluid Power, Mar. 13-16, 1989, Tokyo, Japan. DOI: 10.5739/isfp.1989.79. 
5. M. Rundo, Piloted displacement controls for ICE lubricating vane pumps, SAE Int. J. Fuels Lubr., 2(2): 176-184 (2010). DOI: 10.4271/2009-01-2758.

6. P. Kaliafetis, T. Costopoulos, Modelling and simulation of an axial piston variable displacement pump with pressure control, Mech. Mach. Theory, 30(4): 599-612 (1995). DOI: 10.1016/0094-114X(94)00057-R.

7. N. P. Mandal, R. Saha, S. Mookherjee, D. Sanyal, Pressure Compensator Design for a Swash Plate Axial Piston Pump, J. Dyn. Sys., Meas., Control, 136(2): 021001, (2014). DOI: $10.1115 / 1.4025672$.

8. N.D. Manring, R.E. Johnson, Modeling and designing a variable-displacement openloop pump, J. Dyn. Sys., Meas., Control, 118(2): 267-271 (1996). DOI: 10.1115/1.2802313.

9. L. Gilardino, S. Mancò, N. Nervegna, F. Viotto, An experience in simulation: the case of a variable displacement axial piston pump, $4^{\text {th }}$ JHPS International Symposium on Fluid Power, Nov. 15-17, 1999, Tokyo, Japan. DOI: 10.5739/isfp.1999.85.

10. P. Casoli, M. Pastori, F. Scolari, M. Rundo, Active Pressure Ripple Control in Axial Piston Pumps through High-Frequency Swash Plate Oscillations-A Theoretical Analysis, Energies, 12(7), 1377 (2019). DOI: 10.3390/en12071377.

11. A.Corvaglia, M. Rundo, Comparison of $0 D$ and $3 D$ Hydraulic Models for Axial Piston pumps, Energy Procedia 148: 114-121 (2018). DOI: 10.1016/j.egypro.2018.08.038.

12. E. Frosina, G. Marinaro, A. Senatore, Experimental and numerical analysis of an axial piston pump: A comparison between lumped parameter and $3 D C F D$ approaches, ASME-JSME-KSME $20198^{\text {th }}$ Joint Fluids Engineering Conference, July 28 - Aug. 1, 2019, San Francisco, USA. DOI: 10.1115/ajkfluids2019-5406.

13. F. Pintore, M. Borghi, R. Morselli, A. Benevelli, B. Zardin, F. Belluzzi, Modelling and simulation of the hydraulic circuit of an agricultural tractor, $8^{\text {th }}$ FPNI Ph.D. Symposium on Fluid Power, June 11-13, 2014, Lappeenranta, Finland. DOI: 10.1115/FPNI2014-7848.

14. L.V. Larsson, P. Krus, Displacement Control Strategies of an In-Line Axial-Piston Unit, $15^{\text {th }}$ Scandinavian International Conference on Fluid Power, June 7-9, 2017, Linköping, Sweden.

15. M. Rundo, M.A. Pavanetto, Comprehensive Simulation Model of a High Pressure Variable Displacement Vane Pump for Industrial Applications, ASME 2018 International Design Engineering Technical Conferences \& Computers and Information in Engineering Conference, Aug. 26-29, 2018, Quebec City, Canada. DOI: 10.1115/DETC2018-85099.

16. Siemens Industry Software NV, Simcenter Amesim 2019.1 - Hydraulic Component Design Library User's Manual (2019).

17. M. Rundo, P. Fresia, CFD Analysis of a Pressure Compensator for Variable Displacement Pumps, submitted for the $22^{\text {nd }}$ Australasian Fluid Mechanics Conference, Dec. 6-10, 2020, Brisbane, Australia. 